\title{
Más que paz y guerra: Colombia desde spots politico-electorales televisivos para la Presidencia
}

\section{More than peace and war. Colombia from television political-electoral spots to the Presidency}

\author{
DOI: http://dx.doi.org/10.18566/comunica.n42.a03 \\ Fecha de recepción: 11 de febrero de 2020 \\ Fecha de aceptación: 5 de junio de 2020
}

\section{Resumen}

Los candidatos usan el spot político-electoral para comunicar un imaginario social colectivo que les permita conseguir el mayor número de votos. La campaña electoral de 2014 para la Presidencia de Colombia es recordada por enfatizar el tema de la paz; no obstante, otros temas fueron puestos en la agenda política. El propósito de este trabajo es develar la situación de Colombia comunicada a través de spots político-electorales televisivos de la campaña para la Presidencia de 2014. Se tomaron siete spots de cuatro partidos que participaron en la contienda electoral y se analizaron a través de la teoría de la relevancia, de Sperber y Wilson, para identificar sentidos explícitos e implícitos, ya que la comprensión depende de estos dos significados. Se encontró que la situación del país se expresa principalmente a través de implicaturas, quizá con la intención de llegar a un número más amplio de votantes. El tema más recurrente fue uno coyuntural, la paz. Al mismo tiempo, se observó que la construcción del mensaje en los spots depende de la agenda pública y el candidato/partido los usa a su favor con el fin de imponer su visión general.

\section{Abstract}

The candidates use political-electoral spot to communicate a dominant social collective imaginary with the aim of getting as many votes as he can. comunicación

número 42

Enero - junio

2020 | pp.30-50

\section{Yeny Alexandra Pulido Aguirre}

Doctoranda en Filología: estudios lingüísticos y literarios de la Universidad Nacional de Educación a Distancia (UNED) Docente de la Universidad El Bosque, Colombia Integrante del grupo de investigación FHISCIS-Grupo de Filosofía, Historia y Sociología de las Ciencias yenypulidoa@outlook.es https: / / orcid.org/0000-

0002-2246-8208

Palabras clave Comunicación, spot político-electoral, anuncio de televisión, elecciones, teoría de la relevancia, implicaturas, Colombia.

\section{Keywords}

Communication, politicalelectoral spot, television advertising, elections, relevance theory, Colombia. 
The electoral campaign for Colombian presidency in 2014 is remembered for the emphasis on peace, however, other themes were put on the political agenda. This work aims to unveil the Colombian situation communicated through the television political-electoral spots of the campaign to presidency 2014. Seven spots were analyzed from four parties that participated in the electoral contest. Relevance theory of Sperber and Wilson is used to identify explicit and implicit meanings, because interpretation depends on both senses. Results show this situation is expressed mainly through implicatures, perhaps the intention is to reach more voters. The more recurrent theme was a current one, peace. At the same time, it was noticed that the message construction of the spots depends on the public agenda and the candidate/ party uses it in favor of his/her/its general point of view.

\section{Introducción}

Las elecciones presidenciales de 2014 fueron un hito en la historia de Colombia debido a que el país se proyectaba, bajo la disyuntiva de la paz y la guerra, terminar o continuar con un conflicto armado interno de más de cincuenta años. Desde la campaña electoral para el Senado de la República, que se desarrolló desde enero hasta marzo de 2014, las dos mayores fuerzas políticas del momento se apresuraron a imponer como tema de campaña "la paz", a propósito de las negociaciones que desarrollaba el Gobierno nacional con las FARC-EP (Fuerzas Armadas Revolucionarias de Colombia Ejército del Pueblo) en La Habana. El presidente Juan Manuel Santos, del Partido de la $U$, buscaba ser reelegido, por lo cual su partido usó como tema de campaña "la paz", bajo la promesa de conseguir un acuerdo con las FARCEP. Mientras tanto, el partido de Álvaro Uribe, el Centro Democrático, usó las dos campañas para manifestar su desacuerdo con la paz como la planteaba Santos y se opuso a las negociaciones de La Habana; no obstante, el país vivía otras turbulencias que fueron evidentes en otros temas de la campaña.

Dado que se trataba de la elección del cargo más importante del país, los candidatos usaron spots televisivos con el fin de llegar a todo el territorio nacional. El spot político-electoral, según Contreras (2006, pp. 22 y 29), se constituye en una narración que permite conformar un imaginario social colectivo dominante porque esta narración exhibe una fusión de imaginarios políticos de los electores y los candidatos, con una mezcla de los valores deseados por los electores y los que posee el candidato. En este sentido, los spots pueden ofrecer una radiografía sobre cómo un país es concebido por sus ciudadanos. 
De la anterior idea también cabe resaltar que el candidato es quien domina el contenido del mensaje y, asimismo, quien puede manipularlo. Esto no es una suspicacia: la teoría de la relevancia advierte que el comunicador construye sus enunciados bajo los límites de sus propias capacidades y preferencias con el objetivo de ser comprendido. En este sentido, se esfuerza por crear un mensaje que, además, permita a la audiencia proporcionar evidencia para los efectos cognitivos (confirmación, revisión o abandono de supuestos previos) que él se propone alcanzar, aquellos que le puedan ayudar a alcanzar su meta (Wilson \& Sperber, 2012); en el caso de la publicidad de tipo político-electoral, el candidato (comunicador) selecciona los asuntos y las ideas que quiere que el votante tenga en mente con el fin de conseguir su voto.

Pero este mensaje, en términos de la teoría de la relevancia, solo es una codificación lingüística de lo que el hablante pretende comunicar, una expresión explícita. Es una indicación esquemática del sentido del hablante (Sperber \& Wilson, 1998a, citados en Wilson \& Sperber, 2012, p. 71). El mensaje codificado lingüísticamente se interpreta junto al conocimiento previo, es decir, el contexto cognitivo compartido entre el hablante y su audiencia, lo que genera inferencias que permiten la construcción del sentido del hablante; en la publicidad político-electoral, podría ser la agenda pública de momento. De ahí la importancia de que el candidato realice un estudio en el que identifique y jerarquice "los problemas, [las] necesidades, [las] frustraciones y [las] expectativas de la sociedad, así como los candidatos con quienes mejor se relaciona la posible solución de los mismos" (De Aragón, 2011, p. 66). Esto con el fin de garantizar su adecuación al electorado (ODCA, 2006, p. 69).

Volviendo a los spots político-electorales televisivos a la Presidencia de Colombia en 2014, estudios previos se interesaron en identificar las ideas que estos comunicaron. Uribe y Rincón (2016) estudiaron los spots televisivos de la campaña al Senado y la Presidencia, aquellos de mayor resonancia y difusión, a través del modelo de Beaudoux, D’Adamo y Slavinsky (2005) y los criterios del story-telling, story-living, branding e issues. Los autores encontraron que se dio una confrontación entre dos modos de concebir el país, una que apeló a un futuro de paz y más de lo mismo de Santos. La otra, a un futuro-pasado que consistía en volver a los tiempos de Uribe como acto de restauración moral; Rivas y Roll (2008) tuvieron hallazgos semejantes en los spots televisivos de la campaña a la Presidencia; Hernández Bayter (2015), en los debates para primera y segunda vuelta; Richard (2015), en diferentes piezas publicitarias desde otra perspectiva, en cuanto a la idenficación de temas, obviando las interpretaciones del sentido de los mensajes. El macroproyecto de la MOE (2015) encontró que la paz fue un tema importante en las campañas para el Congreso (Senado y Cámara) y para la Presidencia en diferentes medios de comunicación nacionales y locales. 
No obstante, estos estudios solo se concentran en el tema de la paz, además de no distinguir entre lo dicho explícitamente de lo comunicado implícitamente, pues no usan alguna teoría que permita esa observación. En primer lugar, una campaña no se limita al uso de un solo tema, sino que explora varias posibilidades que podrían ser parte de las preocupaciones de los ciudadanos. En segundo lugar, distinguir entre lo comunicado explícitamente de lo implícitamente permitiría develar lo que el candidato quiere decir de manera inequívoca (o sea, lo explícito) de aquellas ideas que hacen parte del contexto cognitivo compartido por los votantes (lo implícito). Lo explícito, entonces, puede constituirse en una afirmación cuya función puede ser la confirmación, la revisión o el abandono de supuestos previos de los votantes. Lo implícito, por su parte, es parte de ese contexto que se ha fijado previamente en una comunidad de habla. En todo caso, en los dos se pueden observar la concepción que los hablantes tienen sobre un tema dado.

Estas características propias de la comunicación provocan diversas preguntas sobre las ideas comunicadas por los partidos políticos que participaron en la contienda electoral de 2014 a la Presidencia: ¿cuál es la situación del país que se transmite en estos spots? ¿Cuáles son los sentidos explícitos e implícitos sobre la situación del país presentes? ¿Cuál es la visión de país que tiene cada partido político? Así, el propósito de este trabajo es identificar los sentidos explícitos e implícitos sobre la situación de Colombia que circulan en los discursos que los partidos políticos pusieron en sus spots televisivos; este interés es parte de un proyecto más amplio, de tesis doctoral, que incluye el estudio de spots para el Senado en ese mismo año. Para cumplir con este propósito, estos se observan a través de la teoría de la relevancia de Wilson y Sperber $(2005,2012)$, porque esta identifica el contenido explícito y el inferencial, lo que le permite al oyente construir una hipótesis sobre el significado del hablante (los detalles se describen en la metodología).

\section{Campaña electoral a la Presidencia 2014}

La campaña a la Presidencia estuvo precedida por la del Congreso de la República, el cual fue elegido el 9 de marzo de 2014. En esta última se puso a prueba el principal tema de campaña a la Presidencia, las negociaciones de paz entre las FARC-EP y el Gobierno nacional, tema que ya había sido polemizado por el expresidente Álvaro Uribe desde 2012, cuando reveló estas negociaciones (antes secretas).

La promesa de paz hizo que, en las campañas al Congreso, el Partido Liberal Colombiano y el Polo Democrático Alternativo manifestaran el apoyo a 

Uribe- y el Partido Conservador declararon su oposición a las mismas. Para dar mayor fuerza a la oposición, Uribe se lanzó como candidato al Senado mediante una lista cerrada, porque no pudo lanzarse a la Presidencia debido a la restricción constitucional que le impedía elegirse como presidente por tercera vez (Botero, 2018, p. 13) y consiguió una alta votación. Con esta vino la idea de que Óscar Iván Zuluaga, el candidato de Uribe por el Centro Democrático, podría llegar a la Presidencia (Hoyos, 2014, p. 3). Su estrategia de marketing tomó como bandera de campaña los temas que más les preocupaban a los colombianos según las encuestas: seguridad, salud y educación. Como resultado, para finales de abril, el candidato subió en las encuestas en todas las regiones (Hoyos, 2014).

Sin embargo, según Botero (2018, p. 14), tres semanas antes de la elección, las campañas negativas se volvieron la regla cuando se ventilaron dos escándalos. Un mes antes de la primera vuelta, Daniel Coronell denunció que J. J. Rendón, asesor de la campaña de Juan Manuel Santos, "había recibido dinero del narcotráfico para garantizar una negociación entre un grupo de narcotraficantes y el Gobierno nacional". Unos días después, el fiscal general de la nación afirmó que el hacker Andrés Sepúlveda, colaborador de la campaña de Zuluaga, había estado interceptando ilegalmente las comunicaciones de algunos periodistas que cubrían el proceso de paz, los correos de los jefes de prensa del Gobierno y de las FARC-EP (Hoyos, 2014, p. 5).

Enseguida, pese a los escándalos, Santos y Zuluaga pasaron a la segunda vuelta, por lo cual los medios cubrieron la diferencia más notoria entre estos candidatos: el cómo debería ser la salida del conflicto armado interno. Cada candidato representaba el apocalipsis. Los defensores del proceso de paz temían la llegada de Zuluaga al Gobierno, lo que constituía el fin de los diálogos con las FARC-EP y el regreso de Uribe al poder (ahora congresista), quien desestabilizaría la división de poderes y, en el peor de los casos, se anclaría como presidente por muchos años más (Botero, 2018).

En este escenario, cada uno de los candidatos consiguió sus aliados políticos. Clara López, del Polo Democrático Alternativo, manifestó su apoyo público a Santos, seguida por varios miembros de su partido y del Partido Verde, aunque este último no lo hizo de manera oficial. A una semana de la segunda vuelta, Marta Lucía Ramírez, del Partido Conservador, celebró una alianza con Zuluaga (Granada, 2014).

Luego, el cierre de campaña se dio a través de dos vídeos. El primero era un spot conocido como "la loca de las naranjas", en el que una mujer de unos cuarenta años, en una tienda de barrio, exigía educación de calidad para sus hijos. Pero la furia con la que exigía este derecho excedía sus palabras 
y la agresión contra el canasto de naranjas la convirtió en la famosa "loca de las naranjas" (Granada, 2014, p. 8). El spot fue exitoso, pero a los pocos días apareció el vídeo de "doña Mechas", a favor de Santos. Doña Mechas, una señora de setenta años, era la tía de la loca de las naranjas y decía que

[...] ella iba a votar por "JuanPa" porque él sí le iba a dar casa a los viejitos pobres como ella, mientras que "Zurriaga" iba a acabar con esta política. El cierre del video, en el que mandaba a la m... a su sobrina, hizo que doña Mechas llenara las páginas de todos los medios e invadiera todas las redes sociales. Así el Zorro se convirtió en "Zurriaga", Juan Manuel Santos en "Juan Pa" y este último decidió ir a visitarla para cerrar su campaña con un abrazo a doña Mechas (Granada, 2014, p. 10).

Finalmente, Santos ganó y firmó la paz con las FARC-EP. Luego, Colombia se enfrentó a un escenario de reducción de la violencia y las FARC-EP al reto de vivir en una sociedad que desaprueba y recuerda sus crímenes.

\section{Metodología}

Este es un estudio mixto en el que primero se cuantifica la frecuencia de aparición de temas y luego se realiza un trabajo cualitativo. Como estudio cualitativo, describe un fenómeno que ocurre naturalmente para tratar de descubrir sus patrones de comportamiento. El modelo teórico y metodológico que se emplea para develar el sentido es la teoría de la relevancia, porque permite visualizar el sentido explícito e implícito de los enunciados.

Corpus. La muestra seleccionada para este estudio es de tipo no probabilística, ya que "la elección de las unidades de análisis no depende de la probabilidad, sino de causas relacionadas con las características de la investigación" (Vilches, del Río, Simelio, Soler \& Velázquez, 2011, p. 88). Se seleccionaron siete spots político-electorales televisivos de la campaña electoral para la Presidencia de 2014 (ver tabla 1), de cuatro de los cinco partidos políticos que participaron en la contienda', los cuales se caracterizan por hacer mención de la situación de Colombia. La muestra también es de conveniencia, dado que los spots seleccionados son aquellos que estuvieron disponibles en YouTube durante el año 2014 e incluso a la fecha.
1 Ningún spot del Partido Verde fue analizado, debido a que no se evidencia con claridad enunciados que pudieran dar cuenta de la situación de Colombia; aunque proponen temas, en varios casos estos resultan muy vagos. 
Tabla 1. Spots estudiados por partido político

\begin{tabular}{|l|l|}
\hline \multicolumn{1}{|c|}{ Partido } & \multicolumn{1}{|c|}{ Nombre del spot en YouTube } \\
\hline Partido Conservador Colombiano & Marta Lucía Ramírez Presidenta \\
\hline $\begin{array}{l}\text { Unidad Nacional (Partido de la U, } \\
\text { Cambio Radical, Partido Liberal } \\
\text { Colombiano) }\end{array}$ & $\begin{array}{l}\text { Canción Tambores “Juan Manuel Santos } \\
\text { Presidente” }\end{array}$ \\
\cline { 2 - 2 } & Clara López se une a la paz Santos Presidente \\
\hline $\begin{array}{l}\text { Polo Democrático Alternativo, Unión } \\
\text { Patriótica }\end{array}$ & $\begin{array}{l}\text { Una Clara Propuesta para el Agro, Clara López } \\
\text { Presidenta }\end{array}$ \\
\cline { 2 - 2 } & $\begin{array}{l}\text { Vota por la Unión Patriótica, elige la PAZ, elige } \\
\text { el CAMBIO }\end{array}$ \\
\hline Centro Democrático & $\begin{array}{l}\text { Óscar Iván Zuluaga es Centro Democrático } \\
\text { La loca de las naranjas full versión campaña } \\
\text { WFT de Óscar Iván Zuluaga }\end{array}$ \\
\hline
\end{tabular}

Fuente: Elaboración propia

Recogida del corpus. Se realizó entre los años 2014 y 2015 usando el buscador de YouTube; se empleó como comando de búsqueda el nombre del candidato o su partido político, desde donde se arrojaron resultados asociados: los spots de otros candidatos y partidos de la misma contienda electoral. Enseguida se seleccionaron los spots que cumplieran con los siguientes criterios: 1. Impulsa a un candidato o a un partido a la Presidencia de la República en la contienda de 2014. 2. Comunica la situación de Colombia. 3. Tiene una duración menor a 150 segundos.

Diseño de la investigación. Esta investigación sigue las fases generales del análisis del filme de Casetti y di Chio (2007, pp. 32-33), dado que estos explican un marco general de cómo realizar la observación de una pieza audiovisual. A estas fases se les incluyen otros instrumentos que permiten superar cada fase, incluido el proceso global de comprensión propuesto por Sperber y Wilson en su teoría de la relevancia, porque permite rastrear los sentidos explícitos e implícitos -este artículo da cuenta de la fase 4 (recomponer y modelizar)-. A continuación, la descripción de las fases:

1. Segmentar. Es "la subdivisión del objeto en sus distintas partes. Se trata de individuar en una especie de continuo los fragmentos que lo componen, y de reconocer como algo lineal la existencia de una serie de confines" (2007, p. 32); en este proyecto, es la transcripción del mensaje del spot, usando el esquema propuesto por García Beaudoux y otros (2005), el cual diferencia lo dicho a través de las imágenes de lo dicho en el audio, mientras lo describe escena a escena (ver tabla 2). 
Tabla 2. Matriz para la transcripción del spot

\begin{tabular}{|c|c|}
\hline \multicolumn{1}{|c|}{ Imagen } & Audio \\
\hline Escena 1 & $\ldots$ \\
\hline \multicolumn{2}{|c|}{$\ldots$} \\
\hline Escena $2 \ldots$ \\
\hline$\ldots$
\end{tabular}

Fuente: Elaboración propia

2. Estratificar. Es "la indagación 'transversal' de las partes individuales, en el examen de sus componentes internos" (Casetti \& di Chio, 2007, p. 32). En este estudio se siguen dos etapas. En la primera, de la trascripción se toman los enunciados que dan cuenta o implican la situación de Colombia. En la segunda, se aplica el proceso global de comprensión propuesto en la teoría de la relevancia, que implica llegar a la interpretación más relevante para el oyente con el menor esfuerzo (Wilson \& Sperber, 2005, pp. 235-236). Esto es así:

a. Construcción de la explicatura: elaboración de una hipótesis apropiada sobre el contenido explícito usando algunas o todas las siguientes operaciones, solo cuando sea necesario para la comprensión del enunciado:

- Desambiguación: sirve para seleccionar una de las acepciones de un término polisémico. Por ejemplo, la decodificación de

(1) El hombre acababa de terminar la mano, pero estaba húmeda aún.

Debería seleccionar entre una acepción de mano como "parte del cuerpo" o mano como "pasada de pintura".

- Asignación de referente: en el ejemplo anterior, este proceso identificaría el referente correspondiente al sintagma nominal "el hombre". Si el que acaba de terminar la mano resulta ser un pintor, seguramente seleccionaremos la segunda acepción de mano. Si el que la acaba de terminar es un técnico cinematográfico, es muy probable que la acepción seleccionada sea la primera.

- Enriquecimiento: las dos operaciones anteriores no son suficientes para interpretar el enunciado (1) de forma no ambigua. El proceso de enriquecimiento cumple varias funciones; fijémonos en dos de ellas. En primer lugar, hay que situar el enunciado (1) en un lugar y un tiempo determinado. En segundo lugar, hay que precisar el significado de algunas palabras como el adverbio "aún". ¿Cuánto tiempo indica "aún"? Depende de la acepción de "mano" elegida. Supongamos que hemos escogido la primera de 
las acepciones y sabemos que la mano artificial está húmeda "aún". ¿Qué quiere decir esto? ¿Que está húmeda para la escena del pantano? ¿Que está húmeda para pegársela al actor al que se la van a cortar? ¿Que se va a deshacer en cuanto se toque? Estas y otras indeterminaciones se resuelven en este punto (Pons, 2004, p. 48).

- Otros procedimientos de enriquecimiento pragmático: es cualquier otro mecanismo que contribuya a delimitar el significado de una palabra, frase o enunciado.

b. Construcción premisa implicada: elaboración de una hipótesis apropiada sobre los supuestos contextuales pretendidos. Esta surge a partir de las inferencias derivadas de un enunciado, que se constituyen en premisas de un razonamiento.

c. Construcción conclusión implicada: elaboración de una hipótesis apropiada sobre las implicaciones contextuales pretendidas. Esta surge a partir de inferencias que se constituyen en la conclusión de un razonamiento.

Estas dos últimas dan lugar a las implicaturas de un enunciado; es decir, información comunicada en un enunciado, pero no de manera explícita. Es información que el comunicador espera que su interlocutor derive del enunciado.

En esta etapa, la investigadora no profundizó su conocimiento sobre los temas propuestos en las campañas. No vio todos los debates de los candidatos en televisión ni siguió los de radio. No estuvo pendiente de la prensa. Tampoco rastreó información antes de analizar los spots; esto con el fin de interpretar como lo haría la mayoría de los ciudadanos, aunque en este caso se trataría de un ciudadano con estudios universitarios. Así, la investigadora tomó la primera interpretación que vino a su mente, pues así es como se da la interpretación durante el proceso de comunicación.

3. Enumerar y ordenar. Se realiza la recensión sumaria de los elementos observados, lo que supone la descripción de "las correspondencias, las regularidades y los principios que rigen el objeto analizado" (Casetti \& di Chio, 2007, p. 33). En este estudio, se usa Atlas-ti para el tratamiento del material de análisis logrado en la etapa anterior. Primero, el material de trabajo fue codificado para subirlo a la unidad hermenéutica, lo que da cuenta de si el texto es transcripción (lo expresado explícitamente) o implicatura (inferencia), nombre del partido político y el número consecutivo del spot. Segundo, se seleccionaron las citas que dan cuenta de la situación de Colombia y se cifraron a través de la herramienta de códigos (en temas preliminares). Luego, desde la herramienta "superfamilias" se asociaron esos códigos a los temas generales descubiertos en el análisis. 
La nomenclatura de los temas se inspira en la clasificación propuesta por Rivas y Roll (2016, pp. 377-378) y se tomó la denominación de las categorías (temas) paz, infraestructura, educación, salud, empleo, vivienda, campo, corrupción, temas sociales y otros. A esta lista se agrega guerra ${ }^{2}$ como una categoría propia, dado que los discursos del momento giraron en torno a las oposiciones entre paz y guerra. La categoría de empleo de Rivas y Roll se incluye en este estudio como parte de temas sociales.

De Rivas y Roll (p. 379) también se consideran las normas y reglas para el análisis: "las normas son consejos sobre cómo interpretar los resultados del análisis, mientras que las reglas son las prescripciones que se tienen que cumplir para lograr los resultados esperados". En este sentido, las normas para este análisis son: 1. Una cita puede tratar más de un tema. 2. Un spot puede tratar más de un tema. 3. Toda cita (o código) que no corresponda a ningún tema de la lista se clasifica en la categoría de otros; las reglas son: 1. Se deben analizar todos los spots seleccionados. 2. Se debe señalar (a través de la codificación en Atlas-ti en este estudio) el tema en cuanta cita aparezca.

4. Recomponer y modelizar. Consiste en la reconstrucción del "cuadro global que establece los sentidos, a través de una representación sintética de sus principios de construcción y de funcionamiento" (Casetti e di Chio, 2007, pág. 33). En este estudio, se tomaron, por un lado, algunos de los informes que arroja Atlas-ti, tales como tablas de frecuencia de los enunciados explícitos e implícitos. Por otro, informes de citas por temas de campaña. Las tablas permitieron observar los temas más recurrentes y su modo de tratamiento (explícito e implícito). Los informes de citas, por su parte, permitieron tomar las citas de los temas de campaña, insumo que permitió la reconstrucción del sentido de la situación de Colombia, que se muestra como resultados en este artículo.

\section{Resultados y discusión de resultados}

En el análisis se evidenció que la situación de Colombia se expresa principalmente de manera implícita. El Polo Democrático Alternativo y el Centro Democrático fueron los únicos en comprometerse a tratar explícitamente un asunto cada uno, campo y educación respectivamente. Respecto al campo, su aparición en los spots se debe a que se trata de un tema coyuntural en el momento de la contienda electoral por cuenta de los paros agrarios de 2013 y 2014 que afectaron a gran parte del país, pero que lograron el apoyo ciudadano. El Polo aprovechó la oportunidad para advertir que los campesinos estaban quebrados e insinuó que esto se debía a las consecuencias de la firma de los tratados de libre comercio (López O., 2014); en educación, eje de campaña del Centro Democrático, se aseguró
2 En Rivas y Roll, guerra está incluida en la categoría seguridad. 
que la escuela pública era "de pésima calidad" y que esto se debía a que el Gobierno la había abandonado.

El hecho de que la situación del país haya sido principalmente comunicada de manera implícita puede deberse a una o varias de las siguientes razones:

1. Algo natural en la comunicación, según la teoría de la relevancia, ya que el sentido de una oración codificada lingüísticamente no es más que una indicación esquemática del sentido del hablante que tiene la función de permitir, junto al conocimiento previo, la construcción de una interpretación del sentido del hablante, guiado por la expectativa de relevancia dada por el enunciado mismo (Sperber \& Wilson, 1998a, citado por Wilson \& Sperber, 2012, p. 71).

2. Una falta de compromiso del candidato/partido de expresar explícitamente su visión del país, quizá con el fin de evitar entrar en debates sobre su posición. Lo anterior se debe a que, según la teoría de la relevancia, el emisor expresa únicamente aquello que está dispuesto a comunicar.

3. Una estrategia para llegar a un número más amplio de votantes, pues un mensaje general o vago permite al votante guiar su interpretación hacia su conocimiento o creencias más cercanas.

Considerando los sentidos explícitos e implícitos, el tema principal de la contienda electoral fue la paz, le siguieron los temas sociales, la guerra y la educación (ver tabla 3). No es extraño que la paz fuera el tema más recurrente, así como la guerra, puesto que se reconoce que Colombia sufría una guerra con las FARC-EP y previo a la contienda electoral para el Congreso y la Presidencia, Álvaro Uribe les reveló a los ciudadanos que el Gobierno nacional estaba negociando en secreto un acuerdo de paz con la guerrilla, para influir en la agenda pública de las elecciones de 2014. Pero Uribe cayó en su propia trampa, ya que movió a Juan Manuel Santos a justificar su reelección bajo el argumento de garantizar la continuidad de la negociación, porque estaba a punto de lograr el fin del conflicto armado con ese grupo. En consecuencia, Uribe, a través de su partido (el Centro Democrático), también debió tomar posición frente a la paz. No podía negarse rotundamente a esta debido a que se trataba de un hecho esperado por los colombianos, pese a sus reservas. Así, decidió encauzar su oposición al mencionar que los guerrilleros no serían judicializados por sus crímenes en general, mientras se mostraba abierto a la paz con condiciones. Así, la Unidad Nacional y el Centro Democrático lograron imponer sus posiciones y fueron los ganadores de la primera vuelta. En consecuencia, para la segunda consiguieron aliados de otras fuerzas políticas. 
Otros investigadores tuvieron hallazgos semejantes y diferentes: Rivas y Roll (2016, p. 390), en su análisis de contenido de spots de la campaña a la presidencia, afirman que "la paz es el tema que más aparece en las campañas televisivas, tanto en términos globales, como en primera y segunda vuelta". Fueron Santos y Zuluaga quienes se valieron de este tema para guiar su campaña, mientras que para los otros candidatos no fue central. No obstante, este perdió protagonismo en la segunda vuelta a favor de otros temas. Asimismo, Botero (2018, pp. 16-17) afirma que, en la contienda electoral legislativa como la de la Presidencia, los partidos dieron pocas propuestas sustantivas y, en cambio, privilegiaron el tema de la negociación de la paz con las FARC-EP.

Para Richard (2015), quien explora diferentes tipos de piezas publicitarias, el tema de la paz fue impuesto por Santos sin dificultad y recuperado tardíamente por su principal contendor, Zuluaga. De otro lado, algunos resultados de investigación del macroproyecto de la Misión Observatorio Electoral (MOE) (2015), en el que participaron académicos de diferentes regiones del país, pueden ser comparables con los hallazgos de este estudio. Dicho macroproyecto se propuso revisar los medios nacionales y locales de mayor impacto que cubren los procesos electorales y políticos. En prensa escrita, analizaron la sección política, la portada y las secciones de análisis, incluyendo las columnas de opinión. En televisión y radio, se realizó un seguimiento al noticiero de mayor impacto a nivel nacional y local, y los medios digitales en franjas prime. A continuación, se presentan los hallazgos relacionados con el estudio.

La paz fue el tema más tratado en El Heraldo (de Barranquilla), el Nuevo Día (de Tolima), Ecos de Combeima y La Cariñosa de RCN (Martínez Heredia, 2015; González \& Perdomo, 2015). De otro lado, Pachón (2014) advierte que el tema de campaña (en general y en otro estudio) más importante para la segunda vuelta fue el de la paz, promovido por el candidato presidente Santos (y sus aliados), cuyo objetivo era defender el proceso de paz ante la amenaza de que el uribismo llegara al poder para acabar con él.

Este tema fue el segundo de importancia en El Tiempo y Caracol Radio (López, 2015), y tercero en La Crónica del Quindío en cuanto a la agenda de negociación de La Habana (Martínez, 2015, p. 122). Sin embargo, en otros medios, la presencia del tema de la paz fue mínimo, como fue el caso del Diario del Sur (de Nariño), el Diario la Opinión (de Norte de Santander) y Vanguardia Liberal (de Santander), donde aparecieron los temas de la "agenda de negociación" y el "acuerdo humanitario" (Ferreira, 2015; Torres, 2015).

Volviendo a los resultados de este estudio, enseguida se describe la concepción de Colombia descubierta en los spots analizados, tema por tema 
y considerando los sentidos implícitos junto a los explícitos. Lo comunicado implícitamente se expresa aquí a través de los verbos insinuar, sugerir e implicar.

Tabla 3. Temas explícitos e implícitos de la campaña a la Presidencia

\begin{tabular}{|l|c|c|c|}
\hline & Explícito & Implícito & Total \\
\hline Paz & 0 & 45 & 45 \\
\hline Temas sociales & 0 & 25 & 25 \\
\hline Guerra & 0 & 14 & 14 \\
\hline Educación & 2 & 12 & 14 \\
\hline Campo & 2 & 5 & 7 \\
\hline Salud & 0 & 7 & 7 \\
\hline Infraestructura & 0 & 5 & 5 \\
\hline Otros & 0 & 3 & 3 \\
\hline Vivienda & 0 & 2 & 2 \\
\hline Corrupción & 0 & 1 & 1 \\
\hline Totales & 4 & 119 & 123 \\
\hline
\end{tabular}

Fuente: Elaboración propia

Paz, apoyo y oposición. El partido Unidad Nacional sugirió que "no hay paz". Junto a la Unión Patriótica, insinuó que el Gobierno nacional estaba negociando con la guerrilla de las FARC-EP su desmovilización armada. La Unidad Nacional implicó que Colombia estaba en un momento en el que podría conseguir el fin de la guerra, además de insinuar que la paz se podía lograr si se seguían estas negociaciones. En este escenario, Santos dijo que él conseguiría la paz y que había un grupo de colombianos que lo apoyaban en esta empresa, incluida Clara López, su contrincante en la primera vuelta y aliada en la segunda. Por lo tanto, votar por Santos aseguraría la continuación de los diálogos de paz y, por consiguiente, la paz, lo que se constituía en el cambio que soñaban los colombianos. De lo contrario, si se votara por Zuluaga, la paz no se conseguiría.

De otro lado, la Unión Patriótica sugirió que había un momento de disputa política entre quienes apoyaban la paz y quienes no. Respecto al apoyo, el Polo Democrático Alternativo, en un spot de apoyo a la Unidad Nacional, reconoció que el país estaba en guerra y consideraba la posibilidad de que pronto se viviera en paz. Por lo anterior, estaba de acuerdo con dicha negociación; luego sugirió que había un grupo de colombianos a lo largo 
y ancho del país que querían la paz y que se siguiera trabajando para conseguirla, por lo cual darían su voto por el candidato que la promovía, Santos. Entonces, la reelección del presidente significaba seguir con los diálogos de paz.

Por otro lado, en uno de los spots de la Unidad Nacional se insinuó que algunos sectores políticos representados por los seguidores de Álvaro Uribe no querían que la negociación de la paz continuara. Esos sectores políticos apoyaban la candidatura de Zuluaga; al respecto, la Unión Patriótica sugirió que esas opciones políticas seguirían con la guerra.

Rivas y Roll (2016, p. 289) también notan estas dos posturas frente a la paz y la negociación de esta entre el Gobierno y las FARC-EP. Asimismo, Pachón (2014) advierte que Santos (y sus aliados) tenían el objetivo de defender el proceso de paz ante la amenaza de que el uribismo llegara al poder para acabar con él. Richard (29 de septiembre, 2015, p. 98) ve esas dos posturas como "historias relativas al futuro del país basado en la paz (negociada o militar)" en los eslóganes de Zuluaga: 1. "Zuluaga, del lado de los colombianos", que "hace una clara referencia a la traición de Santos a los colombianos con los diálogos de paz que defienden más a los terroristas que a la gente honrada" y 2. "Por una Colombia distinta", que "enfatiza la diferencia entre el país de SANTOS y el que promete ZULUAGA, anunciando el retorno de una nueva era uribista, el retorno de la seguridad y de la autoridad presidencial".

Hoyos (2014), quien narra los sucesos alrededor de la campaña presidencial de 2014, es más específica al contar qué ocurría con los temas de campaña para las presidenciales. Ella afirma que "Óscar Iván Zuluaga, bajo la dirección del expresidente Álvaro Uribe, buscaría la mano dura y la terminación del conflicto por la vía militar, bajo el argumento de buscar una paz sin impunidad, mientras que Juan Manuel Santos continuaría con los diálogos de paz adelantados en La Habana (p. 7)".

Uribe y Rincón (2016), quienes estudiaron los spots más comentados en la contienda legislativa y presidencial, afirman que esta campaña se caracterizó por usar la pedagogía del miedo con mensajes que se batían entre la apuesta por la guerra o por el ideal de paz (p. 227). Nasi y Hurtado (2018) agregan que la campaña del Centro Democrático se propuso desinformar al público respecto a los diálogos de paz, generando temor e indignación por el futuro venidero. Ese partido dijo que Santos le entregaría el país a las FARC-EP, que el Ejército estaba desmoralizado por la humillación que implicaba que ellos se sentaran en la mesa de negociación frente a la guerrilla, e incluso se decía que el Gobierno le iba a bajar el salario y quitar los beneficios a los militares y policías (p. 256). Además, estos autores dicen que "[e]l CD [Centro Democrático] nunca reconoció los aciertos de Santos con el proceso 
de paz ni los gestos de paz de las FARC que daban cuenta de la voluntad política del grupo rebelde" (p. 246).

Temas sociales. El tema relacionado con lo social produjo ideas implícitas relacionadas con la inversión social, el empleo, la pobreza y la atención al país; fue tratado solo por el partido que tradicionalmente lo pone en escena pública (el Polo Democrático Alternativo) y por el que ostentaba el poder en ese momento (Unidad Nacional), que pretendía defender su gestión. La Unidad Nacional, en uno de sus spots proveniente de la candidata Clara López (del Polo Democrático Alternativo), quien se adhirió a la campaña de Juan Manuel Santos, sugirió que el Gobierno colombiano no priorizaba lo social. Enseguida, a través de una implicatura audiovisual y dos visuales, sugería que un grupo de colombianos a lo largo y ancho del país quería que se priorizara lo social. Otro spot, de la Unidad Nacional propiamente, insinuaba que el presidente había hecho mucho para atender las necesidades de los colombianos, aunque reconocía que aún hacía falta mucho por hacer. También, sugería que lo hecho por el Gobierno nacional era construir y regalar casas a los pobres. En cuanto al empleo, insinuaba, a través de una implicatura visual, que el Gobierno había dado oportunidades de trabajo.

En lo relacionado con los dos últimos subtemas, la Unidad Nacional insinuaba, a través de una implicatura visual, que los afrodescendientes eran pobres y que la atención a todo el país consistía en llevar obras a lugares tradicionalmente desatendidos por el Gobierno nacional, aquellos apartados de la sede del Gobierno central (Bogotá) y que habían sido azotados por la guerra. Las obras que se resaltaban eran las casas gratis. Esto significa que Santos no había abandonado el bienestar de las regiones del país. Del mismo modo, se sugería que Germán Vargas visitaba esas regiones. Entonces, los dos candidatos no abandonaban el bienestar de las regiones del país.

Como se observa, la inversión social se entiende como asistencialismo dirigido a los pobres y obras de infraestructura para el desarrollo sin proponer un plan para capitalizarlas. No se proponen estrategias sustentables de desarrollo social y económico que contribuyan por lo menos a una cultura de la paz y una cultura de la autosostenibilidad económica que saque a Colombia de la violencia y la pobreza.

Campo. El tema del campo provocó diferentes posiciones: 1) el Polo Democrático Alternativo afirmó explícitamente que la quiebra de los campesinos se debía a que se importaba en el país todo lo que nosotros antes producíamos y porque los insumos de los campesinos eran muy costosos; 2) el Polo Democrático Alternativo insinuó que el Tratado de Libre Comercio había traído como consecuencia la crisis del campo colombiano. Este tratado se firmó y dio ventaja a la contraparte, permitiendo la entrada 
al país de productos más baratos respecto a los locales: así, los productos colombianos perdieron competitividad y los campesinos dejaron de recibir dinero para continuar con su labor; 3) el Polo Democrático Alternativo afirmó explícitamente: "[el Gobierno nacional está] desconectado con [sic] la gente, [...] los campesinos tienen que ir dos veces a paro, una para que los escuchen en sus necesidades y la otra para que les cumplan los acuerdos a los que se comprometió el gobierno para solucionar los problemas" (López O., 2014); 4) el Polo Democrático Alternativo, en un spot para la Unidad Nacional, sugirió que había un grupo de colombianos a lo largo y ancho del país que quería un nuevo modelo de desarrollo para el campo, debido a que consideraba que el campo no funcionaba bien; y 5) la Unión Patriótica insinuó que quienes explotaban el campo no eran los campesinos.

Evidentemente, los partidos que se preocupan por el campo son los de izquierda (Polo Democrático Alternativo y Unión Patriótica), mientras que los demás no lo consideran. La Unidad Nacional quizá no lo considera porque es el partido del Gobierno del momento, el cual negó que existiera el paro agrario. El Centro Democrático parece interesarse más por la economía y al parecer el campo contribuye a esta.

Guerra. La Unión Patriótica insinuó que el país estaba en guerra y la Unidad Nacional sugirió que la guerrilla de las FARC-EP era la mayor causante de la misma. La Unión Patriótica sugirió que la guerra se daba entre las FARCEP (que peleaban directamente) y el Gobierno nacional (con sus fuerzas armadas), quienes diferían sobre el sistema político que debería seguir el país. Al mismo tiempo, consideraba que era hora de terminarla, así como lo insinuaba también la Unidad Nacional, la cual agregó que quedarse en el pasado significaba continuarla. Por eso, el Gobierno nacional llevó obras a los lugares que habían sido azotados por la guerrilla.

Respecto a los lugares que sufrieron la guerra con las FARC-EP, la Unidad Nacional, a través de implicaturas de mensajes visuales, señaló que eran aquellas regiones apartadas del país que habían sido tradicionalmente desatendidas por el Gobierno nacional, pero el actual Gobierno estaría atendiendo a la población de estas regiones.

La Unión Patriótica y la Unidad Nacional se concentraron en el tema de la guerra con el objetivo de introducir los beneficios de la paz; no obstante, se limitaron a hablar solo de la guerra que había con las FARC-EP, obviando la que se libraba con el ELN. Los candidatos también obviaron las acciones delincuenciales que provocaron los grupos paramilitares y los narcotraficantes, y que se sumaron a la violencia en el país. 
Educación. El Centro Democrático afirmó explícitamente que en Colombia las escuelas (de educación básica y media) públicas eran de pésima calidad, mientras que la Unión Patriótica comunicó lo mismo a través de implicaturas. Para el Centro Democrático, la culpa era del Gobierno, que las abandonaba, y como consecuencia de ello cada día estaban peor. Al respecto, la Unión Patriótica insinuó que la educación de calidad dependía de la posición socioeconómica de la familia de los niños y los jóvenes que iban a la escuela y al colegio, es decir, de contar con recursos económicos para pagar colegiaturas en establecimientos privados que ofrecían un buen servicio.

El Polo Democrático Alternativo, en apoyo a la Unidad Nacional, sugirió que la educación en Colombia no era gratuita en todos sus niveles. La Unidad Nacional, por su lado, implicó a través de imágenes que el Gobierno nacional regalaba computadores y otros materiales a los colegios, lo que sugeriría una inversión en educación.

Las ideas anteriores muestran una preocupación por la educación pública en los niveles de la básica y media, mientras evitan pronunciamientos sobre la crisis de financiación que enfrenta la universidad pública. Es posible que los candidatos no hayan querido considerar este nivel educativo debido a las siguientes razones: 1) la educación básica y media tiene un número más grande de estudiantes comparado con el número de universitarios, 2) una buena educación básica y media les permite a los jóvenes el ingreso a la universidad, lo esperado por los padres y 3) el estigma de violencia que tienen los estudiantes de las universidades públicas, quienes protestan cerrando vías y enfrentándose a la policía usando la fuerza, además de que son asociados por la sociedad con los grupos guerrilleros.

Así, al juzgar las dos primeras razones, es posible que haya un número mayor de votantes entre los padres de los niños y los jóvenes que asisten al colegio comparado con los que van a la universidad. Al mismo tiempo, una buena educación en esos niveles podría ser pensada como un paso para que los jóvenes ingresen a una universidad privada, como una garantía de ascenso socioeconómico.

Salud. El Polo Democrático Alternativo, en un spot para la Unidad Nacional, sugirió que un grupo de colombianos a lo largo y ancho del país quería que se mejorara el sistema de salud, pues este no era humano ni eficiente, ya que no brindaba atención adecuada a las personas. El Partido Conservador Colombiano y la Unión Patriótica también insinuaban que ese sistema no era de buena calidad y no era gratuito.

Quizá la Unidad Nacional rehuía mencionar la crisis del sistema de salud porque pondría en evidencia la falta de diligencia de Juan Manuel Santos en 
su gobierno para solucionarla. Lo mismo ocurrió con el Centro Democrático, cuyo principal líder, Álvaro Uribe, fue promotor de la Ley 100, la cual, de algún modo, causó la actual crisis del sistema.

\section{Conclusiones}

En el análisis se evidenció que la situación de Colombia se expresa principalmente de manera implícita. Este hecho se puede interpretar como algo natural en la comunicación, dado que el enunciado es una clave para la interpretación (Sperber \& Wilson, 1998a, citado por Wilson \& Sperber, 2012, p. 71). Sin embargo, es extraño que muy poco se comunique explícitamente, lo que podría ser una falta de compromiso del candidato para expresar de manera inequívoca su postura. Se trata, en términos de Wilson y Sperber (2005, pp. 227-228), de una selección de información por parte del hablante. Esta característica de la comunicación puede ser empleada en los spots como una estrategia para llegar a un número más amplio de votantes. En este caso, el candidato/partido evita explicitar una idea, planteándola de manera general, con el fin de que el votante complete el sentido según su conocimiento particular del país y acomodando sus creencias al mensaje propuesto por el primero.

Las ideas expresadas de manera explícita son aquellas ampliamente aceptadas por los ciudadanos, tales como que el campo está desprotegido por parte del Gobierno o que la educación (pública) y el sistema de salud no son de calidad. Tales ideas son, entonces, una confirmación de los supuestos de los votantes, cuya función es apelar a la identificación con ellos para conseguir su aprobación.

De otro lado, el principal tema tratado en los spots, tanto explícita como implícitamente, fue uno coyuntural: la paz. La Unidad Nacional y el Centro Democrático impusieron su visión: seguir con las negociaciones de paz y la paz con condiciones, respectivamente. El primero consiguió el apoyo del Polo Democrático Alternativo y la Unión Patriótica, tanto en la primera como en la segunda vuelta, partidos que manifestaron su posición crítica en otros temas que aludían a la gestión del gobierno de Juan Manuel Santos; mientras tanto, el Centro Democrático se mostró en contra del proceso de paz de Santos, y consiguió la adhesión del Partido Conservador Colombiano. Esta situación generó polarización y dejó como consecuencia para el ciudadano la falta de una visión alternativa sobre cómo llegar al final del conflicto armado con las FARC-EP y, en consecuencia, en prospectiva, con los otros grupos ilegales. 
Los ciudadanos se perdieron entre la satanización de la salida negociada a través de discursos de temor y odio y el optimismo de dar fin al conflicto armado con este nuevo intento. Al mismo tiempo, los candidatos evadieron hablar de las causas del conflicto armado con las guerrillas y otras violencias que sufre el país por cuenta de los grupos paramilitares y los narcotraficantes; se limitaron a la negociación que ya se estaba dando con las FARC-EP.

Evidentemente, el mayor tema coyuntural desplazó a un segundo lugar dos asuntos tradicionales de campaña electoral, lo social y la educación, pero que no son menos infalibles para llegar al votante. El Polo Democrático Alternativo resaltó la necesidad de inversión social sin explicitar de qué se trataba. La Unidad Nacional lo vio como la atención a los pobres regalándoles casas (lo que también implica la generación de empleo) y la realización de obras de infraestructura en los lugares apartados del país donde están los pobres. Como se ve, se propuso la inversión social como asistencialismo y obras de infraestructura para el desarrollo sin proponer un plan para capitalizarlas. Ningún partido propuso estrategias sustentables de desarrollo social y económico que contribuyeran a una cultura de la paz y una cultura de la autosostenibilidad económica que sacara a Colombia de la violencia y la pobreza.

En lo referente a la educación, el Centro Democrático y la Unión Patriótica consideraron que la educación pública era de mala calidad. Al mismo tiempo, ninguno de los partidos resaltó la buena calidad de las universidades públicas y sus problemas financieros.

Finalmente, a manera de cierre, se advierte que las implicaturas identificadas no surgen de los spots en sí, sino que dependen de los discursos circundantes (la agenda pública), sobre todo a través de los medios de comunicación masiva que moldean el contexto cognitivo de los usuarios de la lengua. Así, el contenido de los spots no es peligroso por sí mismo; en el caso de los anuncios estudiados, tan solo son piezas de comunicación que pueden fortalecer ideas que se han difundido en otros discursos. El verdadero peligro de la publicidad electoral es seguir la agenda pública acríticamente, porque priva al ciudadano de buscar la verdad y considerar diferentes puntos de vista. Por esta razón, se recomienda continuar el análisis de los enunciados político-electorales en cualquiera de sus formatos e invitar a los candidatos a que apuesten por crear enunciados que ofrezcan conocimientos nuevos a sus votantes y que favorezcan la democracia. 


\section{Referencias}

Botero, F. (2018). Competencia desde la derecha. Las elecciones nacionales del 2014 y el sistema de partidos. En: F. Botero, M. García Sánchéz \& L. Wills-Otero, Polarización y posconflicto: las elecciones nacionales y locales en Colombia, 2014-2017 (pp. 11-28). Bogotá: Universidad de los Andes.

Casetti, F. \& di Chio, F. (2007). Cómo analizar un film. Barcelona: Paidós.

Contreras, J. (2006). El encanto audiovisual en la política: el spot político-electoral televisivo. Disponible en: http://conocimientoabierto.flacso.edu.mx/tesis/120

Diario Nocturno (9 de junio de 2014). La loca de las naranjas, full versión campaña WFT de Óscar Iván Zuluaga [Archivo de video]. Disponible en: https://www.youtube.com/ watch?v=r6VFtK9hxtM.

Ferreira, J. (2015). Cubrimiento de primera vuelta elecciones presidenciales 2014 en el departamento de Santander desde una mirada a los medios impresos Vanguardia Liberal y El Frente. En: Misión de Observación Electoral, Elecciones y medios de comunicación: un zoom a las mujeres en la agenda política (tomo 2) (pp. 105-111). Bogotá: Grupo DAO Digital Limitada.

García Beaudoux, V.; D’Adamo, O. \& Slavinsky, G. (2005). Comunicación política y campañas electorales: estrategias en elecciones presidenciales. Barcelona: Gedisa.

González, R. \& Perdomo, C. (2015). Resultados del seguimiento a los medios Nuevo Día, La Cariñosa RCN, Ecos del Combeima en elecciones presidenciales. En: Misión de Observación Electoral, Elecciones y medios de comunicación: un zoom a las mujeres en la agenda política (tomo 2) (pp. 113-120). Bogotá: Grupo DAO Digital Limitada.

Granada, S. (2014). Elecciones presidenciales en Colombia: las paradojas de la democracia. Iberoamericana. América Latina - España - Portugal, (55), pp. 191-199.

Hernández Bayter, H. (2015). El debate Santos-Zuluaga, el uso de formas y secuencias recurrentes como mecanismos lingüístico-discursivos. Soprag, 3(2), pp. 174-203.

Hernández, I. (2004). Las privatizaciones en Colombia. Apuntes del CENES. semestre I, 24(37), pp. 55-92.

Hoyos, M. P. (2014). Elecciones presidenciales en Colombia (2014): polarización electoral y periodismo espectáculo. Perspectivas, (3), s. p.

López, R. A. (2015). Análisis sobre el cubrimiento de las elecciones presidenciales en Colombia 2014 por los medios de comunicación El tiempo, eltiempo.com y lasillavacia. com. En: Misión de Observación Electoral, Elecciones y medios de comunicación: un zoom a las mujeres en la agenda política (tomo 2) (pp. 50-61). Bogotá: Grupo DAO Digital Limitada.

López O., C. E. (20 de abril de 2014). Una Clara propuesta para el Agro. Clara López presidenta [Archivo de video]. Disponible en: https://www.youtube.com/ watch?v=myUMwX5a1ml.

Martínez Heredia, K. M. (2015). Una mirada reflexiva a las elecciones de Congreso y Presidencia 2014 en el Departamento del Atlántico desde el seguimiendo al mass media impreso El Heraldo. En: Misión de Observación Electoral, Elecciones y medios de comunicación: un zoom a las mujeres en la agenda política (tomo 2) (pp. 39-49). Bogotá: Grupo DAO Digital Limitada. 
Martínez, B. (2015). Resultados seguimiento a medios elecciones a Congreso La Crónica del Quindío. En: Misión de Observación Electoral, Elecciones y medios de comunicación: un zoom a las mujeres en la agenda política (tomo 2) (pp. 121-127). Bogotá: Grupo DAO Digital Limitada.

Misión de Observación Electoral (2015). Elecciones y medios de comunicación: un zoom a las mujeres en la agenda política (tomo 2). Bogotá: Grupo DAO Digital Limitada.

Nasi, C. \& Hurtado, M. (2018). Las elecciones presidenciales del 2014 y las negociaciones de paz con las FARC: cuando la estrategia de polarizar no basta para ganar. En: F. Botero, M. García Sánchez \& L. Wills-Otero, Polarización y posconflicto: las elecciones nacionales y locales en Colombia, 2014-2017 (pp. 229-268). Bogotá: Universidad de los Andes.

Pachón, M. (2014). Las elecciones de Colombia 2014: el tortuoso camino para darle un segundo tiempo al proceso de paz. Iberoameticana, XIV(55), pp. 181-187.

Pastor, F. (2003). Técnico en publicidad (tomo 1). Madrid: Cultural.

Pons, S. (2004). Conceptos y aplicaciones de la Teoría de la Relevancia. Madrid: Arco Libros.

Ramírez, M. L. (2 de mayo de 2014). \#NoMásCorrupción - Marta Lucía Presidenta [Archivo de vídeo]. Disponible en: https://www.youtube.com/watch?v=A3Rk03D11EA.

Reyes, G.; Baena, E. \& Urios, E. (2000). Ejercicios de pragmática (I). Madrid: Arco Libros.

Richard, E. (29 de septiembre de 2015). Elecciones presidenciales en Colombia en 2014: construcción de relatos de paz. Revista Zero, (33), s. p.

Rivas, J. M. \& Roll, D. (2016). Los acuerdos de paz: ¿tema central de los partidos en la campaña presidencial de 2014 en Colombia? Ciencia Política, 11(21), pp. 365-396.

Santos, J. M. (2014). Canción tambores "Juan Manuel Santos Presidente" [Archivo de vídeo]. Disponible en: https://www.youtube.com/watch?v=xaUn7teoGMQ.

Torres, F. (2015). El comportamiento del Diario del Sur. En: Misión de Observación Electoral, Elecciones y medios de comunicación: un zoom a las mujeres en la agenda política (tomo 2) (pp. 90-98). Bogotá: Grupo DAO Digital Limitada.

Unión Patriótica Colombia (11 de enero de 2014). Vota por la Unión Patriótica, elige la PAZ, elige el CAMBIO [Archivo de vídeo]. Disponible en: https://www.youtube.com/ watch?v=To045SeBK1Q.

Valle con Juan Manuel Presidente (7 de junio de 2014). Clara López se une a la Paz Santos Presidente [Archivo de vídeo]. Disponible en: https://www.youtube.com/ watch?v=U8KOZ-GUUAM.

Uribe, C. \& Rincón, O. (2016). Un país, muchos candidatos y un sólo ganador: campaña electoral Colombia 2014 y spots televisivos. En: En O. Leyva, El spot político en América Latina: enfoques, métodos y perspectivas (pp. 193-231). Puerto Vallarta: Universidad de Guadalajara.

Vilches, L.; del Río, O.; Simelio, N.; Soler, P. \& Velázquez, T. (2011). La investigación en comunicación: métodos y técnicas en la era digital. Barcelona: Gedisa.

Wilson, D. \& Sperber, D. (2005). Teoria da relevância. Liguagem em (Dis)curso, 5(esp.), pp. 221-268.

Wilson, D. \& Sperber, D. (2012). Meaning and relevance. New York: Cambridge.

Zuluaga, Ó. I. (10 de marzo de 2014). ¡Óscar Iván Zuluaga es Centro Democrático! [Archivo de vídeo]. Disponible en: https://www.youtube.com/watch?v=Ns)irgvH6hg. 